\title{
Communication
}

\section{EFFECT OF FASTING VERSUS PARENTERAL ALIMENTATION ON THE RAT SMALL INTESTINE}

\author{
Mieko KAWAMURA and Shuichi KIMURA ${ }^{1}$ \\ Laboratory of Nutrition, Faculty of Agriculture, \\ Tohoku University, Sendai, Miyagi 980, Japan
}

(Received June 27, 1980)

\begin{abstract}
Keywords parenteral alimentation, fasting, small intestine
\end{abstract}
The epithelium of the small intestine is known to be influenced by a wide variety of factors, but little is known about the ways in which the functional capacity and continuous cell renewal are regulated. Intraluminal factors, like pancreatic secretions, food substances, bile and bile products, have been shown to cause considerable changes in the small intestinal epithelium. Although oral intake behaviors and the components or volumes of nutrients are recognized to be essential for maintenance of normal function of the small intestine, the mechanism by which this effect is mediated has not been clarified. Intravenous alimentation leads to a significant decrease in total intestinal mass, protein, DNA and digestive enzyme activities, despite the fact that such animals have adequate energy or protein intake.

The present study was undertaken to determine the relationship between the morphological state and physiological changes in the small intestine in rats fed orally, intravenously or fasted.

Six male Sprague-Dawley rats with a mean body weight of approximately $200 \mathrm{~g}$ were prepared for intravenous alimentation by surgically implanting catheters in the jugular vein (1). The animals were fasted for $24 \mathrm{hr}$ before parenteral feeding was begun. Each animal received continuously from 35 to $50 \mathrm{ml}$ of fluid per day; the average fluid intake was $42 \mathrm{ml}$, amounting to $49 \mathrm{kcal}$. Tao et al.(2) determined the energy and nitrogen requirement of growing rats receiving intravenous alimentation by weight gain and nitrogen balance. On the basis of these data, the composition of the intravenous infusates used in this experiment was designed. Actually, final body weights of rats were higher than their initial body weights. Thus, it is correct to consider that the nitrogen balance was positive. Six orallyalimented rats were sham-operated and placed in restraint harnesses identical to those used to support the infusion system in the parenterally fed animals. The oral

\footnotetext{
1 川村美笑子，木村修一
} 
group was fasted for $24 \mathrm{hr}$, placed in individual cages, and allowed an oral ad libitum diet of intravenous solution. Orally-alimented rats received from 35 to $50 \mathrm{ml}$ of fluid per day. Fasted rats drank water freely. Six days following surgery, orally and parenterally fed animals and fasted animals were sacrificed. Each animal was weighed and anesthetized with ether. The first $50 \mathrm{~cm}$ of jejunum was removed and mucosal scrapings were homogenized for enzyme assays. The mucosal homogenates were analyzed for total protein according to the method of Lowry et al.(3) using bovine serum albumin as a standard. DNA was determined by the method of Schmidt and Thannhauser(4) with a modified diphenylamine reaction (5) using highly polymerized calf thymus DNA as a standard. The activities of sucrase (6), alkaline phosphatase (7) and ATPase (6) were measured. All results were expressed as means \pm SE. Statistical analysis was carried out using unpaired Student's $t$-tests.

A portion of the jejunum near the duodenum was examined by scanning electron microscope.

The final body weights among the three groups of animals are shown in Table 1. The average weight gain of $7 \mathrm{~g}$ shown by intravenously fed (I.V.) rats was significantly less than that of orally-alimented $(\mathrm{O})$ rats $(16 \mathrm{~g})$. Fasted $(\mathrm{F})$ rats lost an average of $45 \mathrm{~g}$.

Weights of small intestine are shown in Fig. 1. There was a striking decrease in gut weight per centimeter of jejunum length in the I.V. rats and fasted rats. The small-intestinal weight of I.V. rats was significantly lower than that of orallyalimented rats. In contrast to dry weight, there was no detectable difference in mucosal wet weight between the rats fed intravenously and fasted rats. Mucosal dry weight was $60 \%$ lower in the fasted rats.

Mucosal protein content of the I.V. rats was lower than in rats fed orally. A significant difference was observed in the mucosal protein of I.V. rats compared to fasted rats. In the I.V. rats and fasted rats, the total DNA content of the jejunum mucosa was significantly lower than that of the rats fed orally. There was no significant difference between the I.V. rats and fasted rats, but when expressed as protein content a difference was detectable.

The specific activities of sucrase and alkaline phosphatase of I.V. rats were lower than those of rats fed orally, and greater than the fasted rats (Fig. 2). These alterations of sucrase and alkaline phosphatase were similar to those of mucosal protein and DNA. With regard to ATPase activity, there was no difference between

Table 1. Weight changes of experimental animals.

\begin{tabular}{llll}
\hline Measurement & Orally fed & Fasted & Intravenously fed \\
\hline Initial weight $(\mathrm{g})$ & $205 \pm 4$ & $200 \pm 5$ & $198 \pm 6$ \\
Final weight $(\mathrm{g})$ & $221 \pm 11$ & $155 \pm 8$ & $205 \pm 8$ \\
Weight gain $(\mathrm{g})$ & +16 & -45 & +7 \\
\hline
\end{tabular}




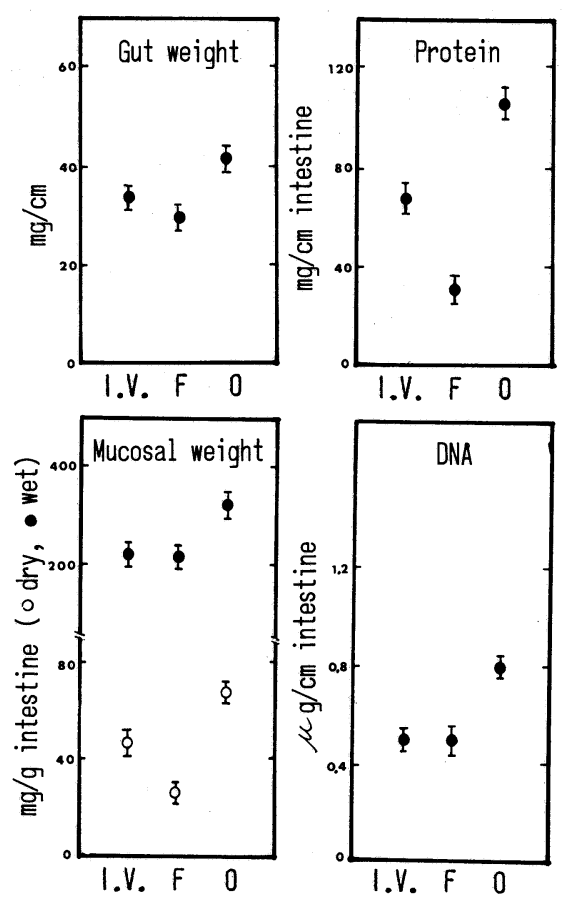

Fig. 1. Effect of fasting versus parenteral alimentation on intestinal weight, mucosal weight, mucosal protein and mucosal DNA.

the I.V. rats and the rats fed orally, contrary to the activities of sucrase and alkaline phosphatase. Fasted rats showed the lowest activity.

To observe changes in the three-dimensional structure of the villi, smallintestinal segments were examined with a scanning electron microscope. As shown in Fig. 3 there are large differences in jejunum villus shape among orally fed rats, fasted rats and intravenously fed rats. The villi of orally fed rats are leaf-like in structure, those in fasted rats are finger-like, and those of intravenously fed rats are conical structures with broad bases and narrow tips. It seems that the villus shape of intravenously fed rats was similar to the villi in the Thiry-Vella fistula by Rijke et al. $(8)$.

From the present study and those of other workers it is clear that intravenous alimentation, as well as fasting has a significant influence on intestinal structure and function. However, in the present work the most striking findings were the increase in gut weight, mucosal dry weight, mucosal protein content, and activities of sucrase and alkaline phosphatase of the rats fed intravenously compared to fasted rats. Moreover, significant differences of the structure of villi were also seen. The decrease in the amount of DNA in the intravenously fed rats indicated that the structural differences may be due to an increase in mucosal cell size. From this result, it may be concluded that intravenous alimentation causes a reduction in the 


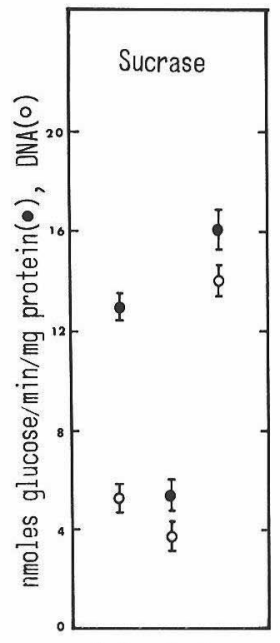

I.V. F 0

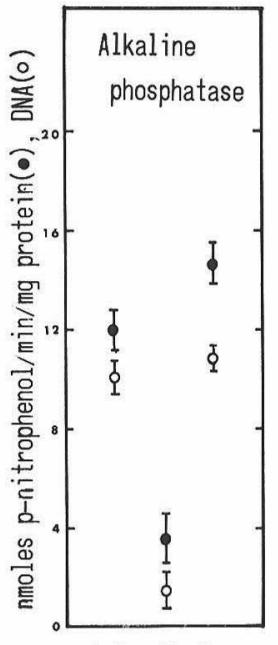

I.V. F 0

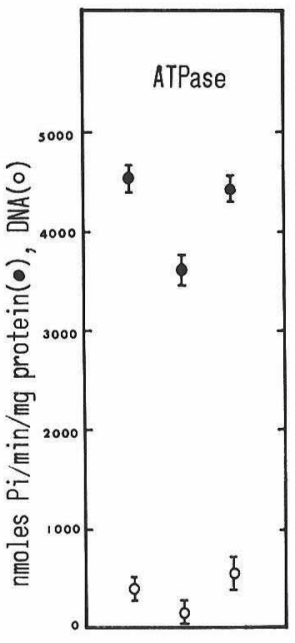

I.V. $\mathrm{F} 0$

Fig. 2. Effect of fasting versus parenteral alimentation on the mucosal enzymes.

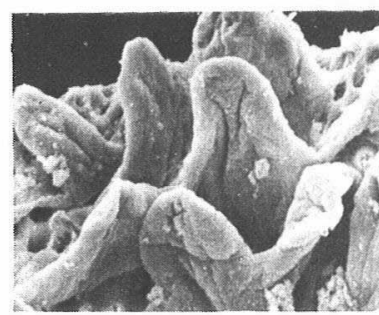

Intravenously fed

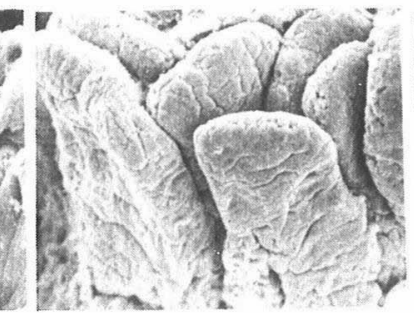

Fasted

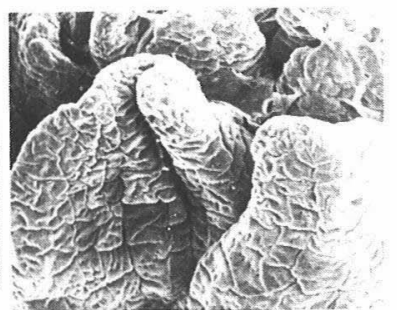

Orally fed

Fig. 3. Scanning electron micrographs of jejunal villi. $(\times 80)$

small-intestinal epithelial cell population. The specific activity of mucosal enzymes was not markedly decreased in the rats fed intravenously as compared to the rats fed orally.

The present investigation indicates that intravenous alimentation maintains the specific activity of mucosal enzyme in the present experimental conditions, that is, during a 6-day experimental period, if animals are fed adequate energy or protein supplies intravenously, although it was apparent that the shape of jejunum villi differed from that of rats fed orally.

The authors thank Mr. K. Nakagawa, Tohoku University, for his technical and professional assistance in assembling the animal harness.

\section{REFERENCES}

l) Steiger, E., Vars, H. M., and Dudrick, J. S. (1972): A technique for long-term intravenous feeding in unrestrained rats. Arch Surg., 104, 330-332. 
2) Tao, R. C., Yoshimura, N. N., Chinn, I. B., and Wolfe, A. M. (1979): Determination of intravenous non-protein energy and nitrogen requirement in growing rats. J. Nutr., 109, 904-915.

3) Lowry, O. H., Rosebrough, N. J., Farr, A. L., and Randall, R. J. (1951): Protein measurement with the Folin phenol reagent. J. Biol. Chem., 193, 265-275.

4) Schmidt, G., and Thannhauser, S. J. (1945): A method for the determination of deoxyribonucleic acid, and phosphoproteins in animal tissues. J. Biol. Chem., 161, 83-89.

5) Croft, D. N., and Lubran, N. (1965): The estimation of deoxyribonucleic acid in the presence of sialic acid: application to analysis of human gastric washings. Biochem. J., 95, 612-620.

6) Fujita, M., Matsui, H., Nagano, K., and Nakao, M. (1971): Asymmetric distribution of ouabain-sensitive ATPase activity in rat intestinal mucosa. Biochim. Biophys. Acta, 233, 404-408.

7) Fujita, M. (1974): The experimental methods of vital membrane. Protein, Nucleic acid, and Enzyme (in Japanese), 5, 284-288.

8) Rijke, R. P. C., Plaisier, H. M., De Ruiter, H., and Galjaard, H. (1977): Influence of experimental bypass on cellular kinetics and maturation of small intestinal epithelium in the rat. Gastroenterology, 72, 896-901. 